\title{
Management of work-related common mental disorders in general practice: a cross-sectional study
}

\author{
M. Rivière ${ }^{1,2^{*}} \mathbb{D}$, Y. Toullic ${ }^{3}$, P. Lerouge ${ }^{3}$, T. Blanchon ${ }^{1}$, A. Leroyer ${ }^{4}$, L. Plancke ${ }^{5}$, T. Prazuck ${ }^{2}$, M. Melchior ${ }^{1}$ and \\ N. Younès $\mathrm{s}^{6,7}$
}

\begin{abstract}
Background: General practitioners (GPs) often manage individuals with work-related common mental disorders (CMD: depressive disorders, anxiety and alcohol abuse). However, little is known about the ways in which they proceed. The aim of this study is to analyze GPs' management and patterns of referral to other health professionals of patients with work-related CMD and associated factors.

Method: We used data from a cross-sectional study of 2027 working patients of 121 GPs in the Nord - Pas-deCalais region in France (April - August 2014). Statistical analyses focused on patients with work-related CMD detected by the GP and examined the ways in which GPs managed these patients' symptoms. Associations between patient, work, GP and contextual characteristics and GPs' management were explored using modified Poisson regression models with robust variance.

Results: Among the 533 patients with work-related CMD in the study, GPs provided psychosocial support to 88.0\%, prescribed psychotropic treatment to $82.4 \%$ and put $50.7 \%$ on sick leave. Referral rates to mental health specialists and occupational physicians were respectively 39.8 and $26.1 \%$. Several factors including patients' characteristics (occupational and sociodemographic), GPs' characteristics and environmental data were associated with the type of management used by the GP.

Conclusion: Our study emphasizes the major and often lonesome role of the GP in the management of patients with work-related CMDs. Better knowledge of the way GPs manage those patients could help GPs in their practice, improve patients care and be a starting point to implement a more collaborative care approach.
\end{abstract}

Keywords: Common mental disorders, Work, Management, Referral, General practice

\section{Background}

Work-related mental disorders have been defined by WHO in 1985 as "multifactorial diseases which may frequently be work-related but also occurring among the general population. They may be partially caused by adverse working

\footnotetext{
* Correspondence: riviere.mat@hotmail.fr

'Sorbonne Université, INSERM, Institut Pierre Louis d'Épidémiologie et de Santé Publique, IPLESP, 75012 Paris, France

${ }^{2}$ Department of Infectious Diseases, Réseau Sentinelles, Centre Hospitalier Régional, d'Orléans 14 avenue de l'hôpital, 45000 Orléans, France

Full list of author information is available at the end of the article
}

conditions, aggravated, accelerated or exacerbated by workplace exposures or they can impair work ability". The definition is vague as adverse work conditions can be a cause and a consequence of this work related-disorder. Mental health disorders, including common mental disorders (CMD), ie depression, anxiety and substance use disorders represent the second leading cause of work-related diseases and the first cause of work-related sickness absence [1-3]. Work-related common mental disorders have been described in occupational medicine literature $[2-6]$ and

(C) The Author(s). 2020 Open Access This article is licensed under a Creative Commons Attribution 4.0 International License, which permits use, sharing, adaptation, distribution and reproduction in any medium or format, as long as you give appropriate credit to the original author(s) and the source, provide a link to the Creative Commons licence, and indicate if changes were made. The images or other third party material in this article are included in the article's Creative Commons licence, unless indicated otherwise in a credit line to the material. If material is not included in the article's Creative Commons licence and your intended use is not permitted by statutory regulation or exceeds the permitted use, you will need to obtain permission directly from the copyright holder. To view a copy of this licence, visit http://creativecommons.org/licenses/by/4.0/ The Creative Commons Public Domain Dedication waiver (http://creativecommons.org/publicdomain/zero/1.0/) applies to the data made available in this article, unless otherwise stated in a credit line to the data. 
primary care [7-10], but patterns of health-care access for patients with work-related mental health disorders use in primary care is not well-known. In many cases the GP is not only the first but also the only health professional contacted [7, 11-15].

According to the WHO's Service Organization Pyramid for an Optimal Mix of Services for Mental Health, every family should have a family doctor, with access to a range of specialist services, both in community and hospital settings. The position of the GP varies considerably across countries and health care systems, as well as depending on patients' expectations and GPs' task performance. In some countries such as the Netherlands, Spain and the UK, the GP is a gatekeeper to specialists and the treatment of patients with psycho-social problems is primarily GPs' task. In others countries such as France, Belgium, Germany and Switzerland, patients can access a specialist directly and visiting the GP is optional [7, 11-15]. However, in France, visiting a GP is a frequent option because of availability and health insurance coverage, which in most cases is at best partial for mental health specialists.

The prevalence of mental disorders in primary care settings has been researched extensively in different countries. Over the years, the prevalence among adults has been documented to range between 10 and $60 \%$; mainly depression (ranging from 5 to 20\%), generalized anxiety disorder (4 to 15\%), harmful alcohol use and dependence (5 to $15 \%$ ), and somatization disorders ( 0.5 to $11 \%)$. In France, primary care is available and covered by the French National Health Insurance system and 2/3 GPs offer psychological support to patients who are depressed [16-18]. They also prescribe drug therapy: antidepressants, anxiolytics or hypnotics [19-21] and psychological treatment [22]. The NICE guidelines recommend that patients with mental health disorders (depression and anxiety) be referred to other specialists (psychologist/psychotherapist) for psychological therapy [23], which is the case of approximately $20 \%$ of patients consulting a GP in different European countries [24, 25]. The most important obstacles to referral are the cost of psychotherapy because private psychologists are often not covered by the health insurance system, delay to have an appointment with a mental health specialist, patients' reluctance to undergo psychotherapy and lack of cooperation between GPs and mental health medical centers [17-20].

In France, there are no systematic data regarding the management of work-related CMD in primary care. Therefore, although psychological support may facilitate return to work, we do not know how often psychological support is actually provided to persons who have workrelated mental health disorders [26]. Occupational medicine services aim to reintegrate persons back at work, measure their disability level and prevent a worsening of the situation [27]. Overall, referral rates to occupational physicians are low (OP) [28] and there is little knowledge regarding collaboration between GPs and occupational medicine services [29].

The aims of this study are thus:

1) to describe the management of patients with workrelated CMD in primary care practice. In particular, we estimate the prevalence of prescription of psychotropic medication, referral to a psychologist/ psychiatrist, sick leave and referral to and OP;

2) to study whether the management of patients with work-related CMD varies with patient, work, contextual or GP characteristics.

\section{Methods}

\section{Design and study population}

The Heracles cross-sectional study was conducted from April to August 2014 among working individuals consulting a GP in the Nord - Pas-de-Calais region, now part of Hauts de France region [10]. Participating GPs were asked to include working patients (at least 6 months of full-time employment during the preceding 12 months) aged from 18 to 65 years they saw during the study period, whatever the reason of appointment. GPs were selected in a way that was proportional to their geographical distribution. The study was proposed to approximately a quarter of GPs in the Nord - Pas-deCalais region $(n=1000)$.

To allow the recruitment of a representative sample of patients, at study initiation, a schedule was provided to each GP indicating the number of patients to include per time slot (16 possible slots). GPs gave each patient an information form, invited them to participate and asked them to sign an inform consent. More details about the recruitment process have previously been published [10].

This study was conducted by the Sentinelles network, part of the INSERM-Paris Sorbonne University research unit UMR-S 1136 [30].

\section{Data}

After their regular appointment, GPs interviewed participating patients for the purposes of the study. Only patients diagnosed by the GP with a work-related CMD in the preceding 12 months or at the time of the appointment (depressive disorder, anxiety disorder or alcohol abuse) were included in the analyses. Collected data were:

Patient management in the preceding 6 months or at the time of the appointment (completed by the GP):

- Psychological support;

- Prescription of psychotropic medication (antidepressants, anxiolytics and hypnotics); 
- Referral to a psychologist/psychiatrist;

- Sick leaves prescription;

- Referral to OP.

Patients' characteristics:

- Sociodemographic (age, gender, family status, family income, level of education);

- Psychiatric and somatic health

- Suicidal risk identified by the MINI [31];

- Occupational grade [32], classified into three groups: blue (farmer/manual worker), pink (technician/ associate professional/clerk/service worker) and white collar workers (manager/professional) [33];

- Company size;

- Job instability assessed based on the type of contract (temporary vs. permanent)

- Reason for medical appointment (somatic, psychological, chronic disease management).

GP's characteristics

- Sociodemographic (age, gender);

- GP's opportunity to collaborate with mental health specialists.

Work characteristics.

We used 20 questions evaluating psychosocial work characteristics, based on the international scientific literature and proposed by experts in the field [34]. These questions explored 6 dimensions of psychosocial work characteristics: work intensity (5 items), emotional demand (6 items), autonomy ( 2 items), social work relations (3 items), conflict of values ( 2 items) and job insecurity ( 2 items).

We also retrieved data concerning contextual characteristics [26, 27]: social deprivation (loneliness, single parenthood, widowhood/divorce) and material deprivation (unemployment, income, level of not graduated).

\section{Statistical analysis}

First, we described the management of work-related CMDs.

Then we considered associations between different types of management of work-related CMDs and explanatory variables: patient-related, work-related, GPrelated and contextual. The dependent variables were different types of management of work-related CMDs: prescription of psychotropic medication; sick leave; referral to an OP; referral to a psychologist/psychiatrist. We used modified Poisson regression with robust variance models [35]: first, in bivariate models all variables $(n=29)$ were tested; second, in multivariate models with a stepwise backward elimination procedure (all characteristics with $p \geq 0.2$ in the bivariate analysis $[n=$ 7 to 10 variables depending on the outcome] were included in multivariate models). Analyses were at first stratified by gender; we did not observe any differences between men and women, therefore gender was controlled for in our statistical analyses.

All analyses were performed using GNU R software version 3.1.1.

\section{Ethical approval}

The study benefits from a standing authorization from the French independent administrative authority protecting privacy and personal data (CNIL), n ${ }^{\circ} 471,393$ to conduct research among GPs and their patients.

\section{Results}

\section{Sample description}

121 GPs completed the study and included 2027 patients. 533 had a work-related CMD and were included in the statistical analyses. Patients were mostly female (57.8\%) and almost half of them were aged between 36 to 50 years. $46.0 \%(n=239)$ had depression, $75.2 \%(n=$ $391)$ anxiety and $8.8 \%(n=46)$ an alcohol-related disorder. Patient, GP, work and contextual characteristics are described in Table 1.

\section{Description of GPs' management of work-related CMDs (Table 2)}

Among the 533 patients with work-related CMDs, 88.0\% $(n=469)$ received psychological support from their GP and $82.4 \%(n=439)$ a prescription for a psychotropic medication. The most prescribed psychotropic medications were anxiolytics (62.1\%), antidepressants (41.8\%) and hypnotics (23.1\%).

$39.8 \%$ of patients were referred to a psychologist or psychiatrist. Sick leave was prescribed to $50.7 \%(n=270)$ of patients, with an average length of 5.36 weeks.

$26.1 \%$ of patients were referred to an occupational physician.

\section{Factors associated with GPs' management of work-related CMDs \\ Prescription of psychotropic medications}

We observed a higher rate of prescription of psychotropic medication for patients with depressive disorders $(\mathrm{RR}=1.08[1.01-1.16])$ and patients who saw their physician for psychological purposes ( $R R=1.25$ [1.14-1.36]). We observed a higher level of prescription of psychotropic medication for older participants (51 to 65 years) compared to those who were 18 to 35 years old (RR = 1.14 [1.03-1.27]) (Table 3). Prescription of psychotropic medication was not associated with any psychosocial work factors. 
Table 1 Description of study population. Héraclès study. Nord Pas-de-Calais, France. 2014

N $\quad \%$

\section{Patient characteristics}

Gender

Male

Female

225

308

Age group

[18-35]

[36-50]

[51-65]

Occupational category

Blue collar

White collar

Pink collar

Educational level

$<$ High school degree

$\geq$ High school degree

Family status

Lives alone

Lives with a partner or parents

Family income

[0-3000 euros]

$3000+$ euros

Number of workers in the company

$$
1 \text { to } 9
$$

$10+$

Psychiatric history (yes vs no)

Somatic history (yes vs no)

Purpose of appointment with GP (yes vs no)

Somatic

Psychological

Chronic disease management

Common mental disorder (yes vs no)

Depression
Anxiety
Alcohol
Suicidal risk (MINI questionnaire)
Past unemployment (yes vs no)
Job instability (yes vs no)

\section{GPs characteristics}

GP's gender
Male
Female
GP's age
[18-49]

46.0

75.2

8.8

25.9

29.5

38.4
Table 1 Description of study population. Héraclès study. Nord Pas-de-Calais, France. 2014 (Continued)

\begin{tabular}{lcc}
\hline & $\mathrm{N}$ & $\%$ \\
\hline $50+$ & 339 & 63.6 \\
Opportunity to work with mental health specialists & \\
High & 291 & 56.4 \\
Low & 225 & 43.6 \\
Contextual characteristics & & \\
Social deprivation & & \\
High & 159 & 29.8 \\
Low & 374 & 70.2 \\
Material deprivation & & \\
High & 266 & 49.9 \\
Low & 267 & 50.1
\end{tabular}

Work characteristics

Work intensity

$$
\text { High }
$$

Low

Emotional demands

$$
\text { High }
$$

Low

Autonomy

Low

Conflict of values

$$
\text { High }
$$

$$
\text { Low }
$$

Social relationships at work

$$
\text { High }
$$

67

$$
\text { Low }
$$

Job Insecurity

$$
\text { High }
$$

\section{Referral to a psychologist or psychiatrist}

There was a higher rate of referral to a psychologist or psychiatrist for patients with depressive disorders compared to patients with other CMDs $(\mathrm{RR}=1.71$ [1.342.18]), patients who saw their GP for psychological purposes $(\mathrm{RR}=1.32[1.06-1.65])$ and those with a suicidal risk $(R R=1.49$ [1.22-1.82]). Patients with a somatic or psychiatric history were more likely to be referred to a psychologist or psychiatrist with RRs of respectively 1.24 and 1.26. There was a higher rate of referral for patients whose GP had more opportunity to collaborate with mental health specialists $(\mathrm{RR}=1.32[1.05-1.66])$. Patients living in an area with high material deprivation were more likely to be referred to a psychologist or psychiatrist $(\mathrm{RR}=1.32[1.08-$ 
Table 2 Description of GPs' management of work related common mental disorders. Héraclès study. Nord - Pas-de-Calais, France. 2014

\begin{tabular}{lll}
\hline & N & $\%$ \\
\hline Psychological support (yes vs no) & 469 & 88.0 \\
Prescription of psychotropic medication (yes vs no) & 439 & 82.4 \\
Antidepressants & 223 & 41.8 \\
Anxiolytics & 331 & 62.1 \\
Hypnotics & 123 & 23.1 \\
Sick leave prescription related to mental disorders (yes vs no) & 270 & 50.7 \\
Average length of sick leave (in weeks) & 5.36 \\
Referral & & \\
$\quad$ To occupational physician & 139 & 26.1 \\
To psychologist/psychiatrist & 212 & 39.8 \\
To psychiatric emergency & 16 & 3.0 \\
\hline
\end{tabular}

1.62]) (Table 4). Referral to a psychologist or psychiatrist was not associated with any psychosocial work factors.

\section{Sick leave}

Patients with depressive disorder had a higher rate of sick leave $(\mathrm{RR}=1.18[1.01-1.39])$ compared to patients with other work-related CMDs as did patients who saw their physician for psychological reasons $(R R=1.83$ [1.49-2.24]). For patients working in a big company the relative risk (RR) of sick leave was higher compared to patients working in smaller companies. Psychosocial work factors such as high emotional demands and high social relationships at work were significantly associated with sick leave with RRs respectively of 1.33 and 0.65 (Table 5).

\section{Referral to an occupational physician}

The rate of referral to an OP was higher for patients with depressive disorder compared to patients with other work-related CMDs $(\mathrm{RR}=1.34$ [1.00-1.79]). White collar workers had a lower rate of referral compared to blue collar workers $(\mathrm{RR}=0.51[0.31-0.88])$. High work

Table 3 Factors associated with the prescription of psychotropic medication, Héraclès study, France, 2014. Poisson regression models $(n=518)$

\begin{tabular}{lllr}
\hline & $R^{*}$ & Cl 95\% & P \\
\hline Age group & & & \\
{$[18-35]$} & 1.00 & - & 0.56 \\
{$[36-50]$} & 1.03 & {$[0.93-1.14]$} & \\
{$[51-65]$} & 1.14 & {$[1.03-1.27]$} & \\
Psychological purpose of consultation & 1.25 & {$[1.14-1.36]$} & $<0.01$ \\
Depression detected by GP & 1.08 & {$[1.01-1.16]$} & 0.04 \\
\hline
\end{tabular}

* adjusted on gender intensity was significantly associated with OP referral $(\mathrm{RR}=1.41$ [1.06-1.88]) (Table 6).

\section{Discussion \\ Summary}

Our study reports the management of patients with work-related CMD in primary care. GPs provided psychological support to nearly $90 \%$ of patients; they prescribed psychotropic medication to more than $80 \%$. They referred approximately $40 \%$ of patients to a psychologist or psychiatrist. Sick leave was prescribed to more than half of the patients, with an average length of 5.36 weeks. $26.1 \%$ of patients were referred to an OP. Low referral rates to psychologists, psychiatrists and OPs indicate that GPs often manage these patients alone. This could be the GPs choice if he or she has sufficient skills in this area, or a sign of lack of cooperation with mental health and occupational health specialists.

No work-related factors were associated with neither psychotropic medication prescription nor referral to a psychologist or psychiatrist. Work-related factors were associated with sick leave prescription and referral to an OP. Higher rates of sick leave were related with suicidal risk, employment in a large company, as well as emotional demands and social relationships at work. Referral to an OP was more frequent for patients with depressive disorders and high work intensity, while it was lower for white collar workers.

\section{Comparison with existing literature GP's management of patients with work-related CMD}

Our results are consistent with previous studies on GP's management of patients with CMD, indicating that there is little special management in case of work-related CMD, compared to CMDs outside the context of work. In France, on average, more than $90 \%$ of the GPs prescribed psychotropic medication to patients with depressive disorders [36]. Another study found that $80 \%$ of patients receiving antidepressants or tranquilizers had a depressive or anxiety disorder diagnosed by their GP [19].

Rates of psychological support observed in our study in case of work-related CMD are also consistent with the scientific literature in CMD. In France, as in other countries, 2/3 of GPs offer their patients psychological support, which is often associated with the prescription of psychotropic medication [16-18, 37]. Psychological support is particularly important in case of work-related issues, as it helps in the process of returning to work [26].

Referral rates to psychiatrists or psychologists in case of work-related CMD are also consistent with previous studies $[25,28]$. Low rates of referral could be related to difficulties in accessing these specialists, lack of coverage by the national health insurance system, patients' refusal 
Table 4 Factors associated with referral to a psychologist or psychiatrist. Héraclès study. Nord - Pas-de-Calais, France. 2014. Poisson regression models $(n=475)$

\begin{tabular}{|c|c|c|c|}
\hline & $\mathrm{RR}^{*}$ & $\mathrm{Cl} 95 \%$ & $p$ \\
\hline Depression detected by GP & 1.71 & {$[1.34-2.18]$} & $<0.01$ \\
\hline Suicidal risk & 1.49 & [1.22-1.82] & $<0.01$ \\
\hline Psychological purpose of consultation & 1.32 & {$[1.06-1.65]$} & 0.01 \\
\hline Psychiatric history & 1.26 & {$[1.01-1.57]$} & 0.04 \\
\hline Somatic history & 1.24 & {$[1.02-1.52]$} & 0.03 \\
\hline Opportunity to work with mental health specialists & 1.32 & {$[1.05-1.66]$} & 0.02 \\
\hline Material deprivation & 1.32 & {$[1.08-1.62]$} & $<0.01$ \\
\hline
\end{tabular}

* adjusted on age and gender

or lack of the GPs lack of training $[18,36]$. This could also be the GP's choice [15].

Two results should be highlighted in the specific context of work-related CMDs.

First, our study reports a low rate of referral to OPs that could be explained by suspicion about the physician's lack of impartiality. OPs are often employed by companies and could be perceived as subject to their employer. Additionally, GPs may not know the role of OPs in detail $[28,38]$.

Second, rates of sick leave in case of work-related CMD are consistent with a Norwegian study where $45 \%$ of patients with CMD have a sick leave prescribed by the GP [39]. The average length of sick leave is compatible with data from the French national health insurance, showing that there is a high rate of long term sick leave for individuals with CMD [40].

\section{Factors associated with GP's management of patients with work-related CMD}

Our study highlights several factors associated with the management of patients with work-related CMDs. In the literature, very few studies explored factors associated with GPs' management of CMDs and almost none for work-related issues and referral to OP by GP.

Table 5 Factors associated with sick leave. Héraclès study. Nord - Pas-de-Calais, France. 2014. Poisson regression models ( $n=$ 502)

\begin{tabular}{llll}
\hline & $\mathrm{RR}^{*}$ & $\mathrm{Cl} 95 \%$ & $\mathrm{P}$ \\
\hline Depression detected by GP & 1.18 & {$[1.01-1.39]$} & 0.05 \\
Psychological purpose of consultation & 1.83 & {$[1.49-2.24]$} & $<0.01$ \\
Number of workers in the company & & & \\
1 to 9 & 1.00 & - & 0.04 \\
$10+$ & 1.26 & {$[1.01-1.58]$} & \\
Emotional demands at work (high vs low) & 1.33 & {$[1.13-1.56]$} & $<0.01$ \\
Social relationships at work (high vs low) & 0.65 & {$[0.46-0.92]$} & 0.01 \\
\hline
\end{tabular}

* adjusted on age and gender
The relationship between the prescription of psychotropic drugs and the patient's age in case of depression [41] or psychologic complaints and more severe mental disorders [42] has previously been described.

Referral to a mental health specialist has been associated with psychiatric history, depressive symptoms, suicidal risk [43, 44] and the opportunity to work with mental health specialists [45].

For sick leave, our results indicate that GPs follow trends that have been highlighted among workers. Depressive disorders are the first cause of sickness certification for CMDs [46]. It is interesting to note that GPs take into account dimensions of work to prescribe sick leave: they are more frequent in case of low social support at work and high psychological demands [47, 48]. The size of the company is also important, indicating that it is easier to be absent from work when there are colleagues who can replace you. This has been highlighted in a Japanese study [49].

Our study explores for the first time referral to OPs by GPs. We show that this is associated with workcharacteristics. Fewer referrals to OPs for white collar have to be explored further. They may be related to mistrust of the relationship between OPs and the company, especially for managers. GP contact the OP more frequently in case of higher work intensity, which makes sense when trying to adapt working conditions.

Table 6 Factors associated with referral to an occupational physician. Héraclès study. Nord - Pas-de-Calais, France. 2014. Poisson regression models $(n=485)$

\begin{tabular}{llll}
\hline & $\mathrm{RR}^{*}$ & $\mathrm{Cl} 95 \%$ & $\mathrm{P}$ \\
\hline Occupational category & & & \\
$\quad$ Blue collar & 1.00 & - & 0.03 \\
White collar & 0.51 & {$[0.31-0.88]$} & \\
$\quad$ Pink collar & 0.91 & {$[0.58-1.42]$} & \\
Depression detected by GP & 1.34 & {$[1.00-1.79]$} & 0.05 \\
Work intensity (high vs low) & 1.41 & {$[1.06-1.88]$} & 0.02 \\
\hline
\end{tabular}

* adjusted on age and gender 


\section{Strengths and limitations}

As described in previous articles based on the Héraclès study, some limitations have to be acknowledged [10, 50, 51]. First, there is possible selection bias of GPs. Participating GPs could be especially interested in CMDs because of personal interest or patients' rate of CMDs. Therefore, participating GPs could have a better experience of managing those patients and thus a different practice towards them. However, physicians who participated were representative of the Nord - Pas-de-Calais region GPs, thus limiting this bias. Second, our study was conducted in the Nord - Pas-de-Calais, a region with a low density of medical health specialist [52]. This could influence GPs' practice, especially for referral to other health professionals. Moreover, low income in this area could led to a more frequent management of CMDs by the GP. Another possible limitation is the absence of standard procedures for GPs to diagnose CMD. In France such procedures do not exist in primary care. Finally the definition of the link between work and CMDs could be a limiting factor, even if we relied on the WHO definition of work-related disorders and the scientific literature $[1,53-55]$. Indeed, there is no validated and consensual definition of work-relatedness of psychological difficulties.

Despite these limitations, the results of this study are valuable, because to our knowledge, this is the first study in Europe to study the management of patients with work-related CMDs by the GP. Moreover, contrary to studies in occupation settings, our study was conducted among primary care patients, which include a large panel of workers in the labour force including workers who have a poor relation with occupational practice (independent workers, workers in small companies or workers who do not have an OP, etc.). An international study shows that the average occupational health services coverage of workers is $24.8 \%$ [55]. Finally, study questionnaires were completed by the GP who is often the referring physician and is well informed of the patient's medical history and can assess if the disorder is related to work.

\section{Conclusion}

Our study is one of the first to study the management of work-related CMDs by GPs. Our results emphasize the major role of GPs in the management of those patients (psychological support, psychotropic use and sick leaves), with weak referrals to other mental health specialists or OPs. There is little special management in case of work-related CMDs, compared to CMDs without the context of work, except for sick leave and referral to an OP. Factors associated with the different types of management could help to better understand the way GPs manage those patients and could be a starting point to implement collaborative care, especially with OP.

\section{Abbreviations}

CMD: Common mental disorders; GP: General practitioner; OP: Occupational physician; RR: Relative risk

\section{Acknowledgements \\ The authors thank all the participating GPs of the Nord- Pas-de-Calais region and their patients who participated to the Héraclès study. The authors thank the department of general practice of Lille's University and the regional union of health professional of GP's (URPS-ML) of the Nord-Pas-de-Calais re- gion for their involvement in the GP recruitment phase. The authors also want to thank the Héraclès study scientific committee members who con- tributed to the brainstorming and the set-up of this survey.}

\section{Authors' contributions}

Study concept and design: MR, NY, MM, AL, TB, LP, PL, TP. Data analysis and collection: MR, YT. Drafting of the manuscript: MR. Critical revision of the manuscript: NY, MM, AL, LP. All authors have approved the final manuscript.

\section{Funding}

This work was supported by the Nord-Pas-de-Calais regional health agency (ARS) ( $\left.{ }^{\circ} 2589\right)$. They were member of the scientific committee thus validating the design of the study and the methodology used to collect and analyse the data.

\section{Availability of data and materials}

The datasets generated and/or analysed during the current study are not publicly available but are available from the corresponding author on reasonable request.

\section{Ethics approval and consent to participate}

The Sentinelles network has a standing authorization from the French independent administrative authority protecting privacy and personal data (CNIL), n471 393 to conduct research among GPs and their patients. A written consent to participate was obtained from the participant.

Consent for publication

Not applicable.

\section{Competing interests}

The authors declare that they have no competing interests.

\section{Author details}

'Sorbonne Université, INSERM, Institut Pierre Louis d'Épidémiologie et de Santé Publique, IPLESP, 75012 Paris, France. ${ }^{2}$ Department of Infectious Diseases, Réseau Sentinelles, Centre Hospitalier Régional, d'Orléans 14 avenue de l'hôpital, 45000 Orléans, France. ${ }^{3}$ University department of general practice, Université Lille 2, Lille, France. ${ }^{4}$ Univ. Lille, CHU Lille, Institut Pasteur de Lille, EA 4483 - IMPECS - IMPact de I'Environnement Chimique sur la Santé humaine, F-59000 Lille, France. ${ }^{5}$ Regional Federation of Research in Psychiatry and Mental Health Hauts-de-France, Lille, France. ${ }^{6}$ Université de Versailles Saint-Quentin, Université Paris Saclay, CESP, Team DevPsy, 94807 Villejuif, France. ${ }^{7}$ Centre Hospitalier de Versailles, Hospital Academic Unit of psychiatry for adults, Le Chesnay, France.

Received: 19 July 2019 Accepted: 19 June 2020

Published online: 02 July 2020

\section{References}

1. Hussey L, Turner S, Thorley K, McNamee R, Agius R. Work-related ill health in general practice, as reported to a UK-wide surveillance scheme. $\mathrm{Br} J$ Gen Pract J R Coll Gen Pract sept. 2008;58(554):637-40.

2. Ikonen $A$, Räsänen $K$, Manninen $P$, Rautio M, Husman P, Ojajärvi A, et al. Work-related primary care in occupational health physician's practice. J Occup Rehabil mars. 2012;22(1):88-96.

3. Valenty M, Homère J, Mevel M, Dourlat T, Garras L, Brom M, et al. Surveillance Programme of work-related diseases (WRD) in France. Saf Health Work mars. 2012;3(1):67-70.

4. Stansfeld S, Candy B. Psychosocial work environment and mental health--a meta-analytic review. Scand J Work Environ Health déc. 2006;32(6):443-62. 
5. Taghinejad H, Suhrabi Z, Kikhavani S, Jaafarpour M, Azadi A. Occupational mental health: a study of work-related mental health among clinical nurses. J Clin Diagn Res JCDR sept. 2014;8(9):WC01-3.

6. Hounsome B, Edwards RT, Hounsome N, Edwards-Jones G. Psychological morbidity of farmers and non-farming population: results from a UK survey. Community Ment Health J août. 2012:48(4):503-10.

7. Toft T, Fink P, Oernboel E, Christensen K, Frostholm L, Olesen F. Mental disorders in primary care: prevalence and co-morbidity among disorders. results from the functional illness in primary care (FIP) study. Psychol Med. août 2005:35(8):1175-84.

8. Alkhadhari S, Alsabbrri AO, Mohammad IHA, Atwan AA, Alqudaihi F, Zahid MA. Prevalence of psychiatric morbidity in the primary health clinic attendees in Kuwait. J Affect Disord mai. 2016:195:15-20.

9. Milanović SM, Erjavec K, Poljičanin T, Vrabec B, Brečić P. Prevalence of depression symptoms and associated socio-demographic factors in primary health care patients. Psychiatr Danub mars. 2015;27(1):31-7

10. Rivière $M$, Plancke $L$, Leroyer $A$, Blanchon $T$, Prazuck $T$, Prouvost $H$, et al. Prevalence of work-related common psychiatric disorders in primary care: the French Héraclès study. Psychiatry Res. 2018;259:579-86.

11. Walters P, Ashworth M, Tylee A. Ethnic density, physical illness, social deprivation and antidepressant prescribing in primary care: ecological study. Br J Psychiatry J Ment Sci sept. 2008;193(3):235-9.

12. Ansseau M, Dierick M, Buntinkx F, Cnockaert P, De Smedt J, Van Den Haute $M$, et al. High prevalence of mental disorders in primary care. J Affect Disord janv. 2004;78(1):49-55.

13. Sundquist J, Ohlsson H, Sundquist K, Kendler KS. Common adult psychiatric disorders in Swedish primary care where most mental health patients are treated. BMC Psychiatry. 30 2017;17(1):235.

14. Combs H, Markman J. Anxiety disorders in primary care. Med Clin North Am sept. 2014;98(5):1007-23.

15. Verhaak PFM, van den Brink-Muinen A, Bensing JM, Gask L. Demand and supply for psychological help in general practice in different European countries: access to primary mental health care in six European countries. Eur J Public Health juin. 2004;14(2):134-40.

16. Hickie IB, Davenport TA, Naismith SL, Scott EM, Hadzi-Pavlovic D, Koschera A. Treatment of common mental disorders in Australian general practice. Med J Aust. 16 2001;175(S1):S25-30.

17. van Rijswijk E, Borghuis $M$, van de Lisdonk E, Zitman F, van Weel C. Treatment of mental health problems in general practice: a survey of psychotropics prescribed and other treatments provided. Int J Clin Pharmacol Ther janv. 2007;45(1):23-9.

18. Dumesnil H, Cortaredona S, Cavillon M, Mikol F, Aubry C, Sebbah R, et al. La prise en charge de la dépression en médecine générale de ville. :8.

19. Norton J, de Roquefeuil G, David M, Boulenger J-P, Ritchie K, Mann A. [Prevalence of psychiatric disorders in French general practice using the patient health questionnaire: comparison with GP case-recognition and psychotropic medication prescription]. L'Encephale. déc 2009;35(6):560-9.

20. Bushnell J, McLeod D, Dowell A, Salmond C, Ramage S, Collings S, et al. The treatment of common mental health problems in general practice. Fam Pract févr. 2006;23(1):53-9.

21. Alson AR, Robinson DM, Ivanova D, Azer J, Moreno M, Turk ML, et al. Depression in primary care: strategies for a psychiatry-scarce environment. Int J Psychiatry Med. 2016;51(2):182-200

22. Spiers N, Qassem T, Bebbington P, McManus S, King M, Jenkins R, et al. Prevalence and treatment of common mental disorders in the English national population, 1993-2007. Br J Psychiatry J Ment Sci. 2016;209(2): 150-6.

23. Clark DM. Implementing NICE guidelines for the psychological treatment of depression and anxiety disorders: the IAPT experience. Int Rev Psychiatry Abingdon Engl août. 2011;23(4):318-27.

24. Kendrick T, Dowrick C, McBride A, Howe A, Clarke P, Maisey S, et al. Management of depression in UK general practice in relation to scores on depression severity questionnaires: analysis of medical record data. BMJ. 19 mars 2009:338:b750.

25. Alonso J, Lépine J-P, ESEMeD/MHEDEA 2000 Scientific Committee. Overview of key data from the European Study of the Epidemiology of Mental Disorders (ESEMeD). J Clin Psychiatry. 2007;68 Suppl 2:3-9.

26. Arends I, Bruinvels DJ, Rebergen DS, Nieuwenhuijsen K, Madan I, NeumeyerGromen A, et al. Interventions to facilitate return to work in adults with adjustment disorders. Cochrane Database Syst Rev. 12 déc 2012;12: CD006389.
27. Matsuda S. [The occupational physician in France]. J UOEH. oct 2013;35 Suppl:67-72.

28. Verger P, Ménard C, Richard J-B, Demortière G, Beck F. Collaboration between general practitioners and occupational physicians: a comparison of the results of two national surveys in France. J Occup Environ Med févr. 2014;56(2):209-13.

29. Leclercq G. La santé au travail Vision nouvelle et professions d'avenir Propositions pour des formations et un réseau de recherche en phase avec les missions - Ministère du Travail, de la Solidarité et de la Fonction Publique, 2010;94

30. Flahault A, Blanchon T, Dorléans Y, Toubiana L, Vibert JF, Valleron AJ. Virtual surveillance of communicable diseases: a 20-year experience in France. Stat Methods Med Res oct. 2006;15(5):413-21.

31. Sheehan DV, Lecrubier $Y$, Sheehan $\mathrm{KH}$, Amorim $P$, Janavs J, Weiller $E$, et al. The Mini-International Neuropsychiatric Interview (M.I.N.I.): the development and validation of a structured diagnostic psychiatric interview for DSM-IV and ICD-10. J Clin Psychiatry. 1998;59 Suppl 20:22-33;quiz 34-57.

32. INSEE. Nomenclature des professions et catégories socioprofessionnelles PCS [Internet]. 2003 [cité 6 déc 2019]. Disponible sur: https://www.insee.fr/ fr/information/2400059.

33. Min K-B, Park S-G, Hwang SH, Min J-Y. Precarious employment and the risk of suicidal ideation and suicide attempts. Prev Med févr. 2015;71:72-6.

34. Askenazy P, Baudelot C, Brochard P, Brun J-P, Davezies P, Falissard B, et al. Mesurer les facteurs psychosociaux de risque au travail pour les maîtriser. :223.

35. Zou G. A modified poisson regression approach to prospective studies with binary data. Am J Epidemiol. 1 avr 2004;159(7):702-6.

36. Mercier A, Kerhuel N, Stalnikiewitz B, Aulanier S, Boulnois C, Becret F, et al. [Obstacles to effective treatment of depression. A general practitioners' postal survey in the north-west region of France]. L'Encephale. juin 2010;36 Suppl 2:D73-82

37. Dumesnil $H$, Cortaredona S, Verdoux H, Sebbah R, Paraponaris A, Verger $\mathrm{P}$. General practitioners' choices and their determinants when starting treatment for major depression: a cross sectional, randomized case-vignette survey. PLoS One. 2012;7(12):e52429.

38. Beach J, Watt D. General practitioners and occupational health professionals. BMJ. 9 août 2003;327(7410):302-3.

39. Gjesdal S, Holmaas TH, Monstad K, Hetlevik $\varnothing$. GP consultations for common mental disorders and subsequent sickness certification: registerbased study of the employed population in Norway. Fam Pract. 2016;33(6): 656-62.

40. Serrano DR-J, Lafon DJ-C, Ronin DJ, Durieux DB, Pollini DJ, Goustiaux DZ, et al. Description des populations du régime général en arrêt de travail de 2 à 4 mois. 2004;35

41. Walters $K$, Falcaro M, Freemantle $N$, King M, Ben-Shlomo $Y$. Sociodemographic inequalities in the management of depression in adults aged 55 and over: an analysis of English primary care data. Psychol Med. 2018;48(9):1504-13.

42. Linden M, Lecrubier Y, Bellantuono C, Benkert O, Kisely S, Simon G. The prescribing of psychotropic drugs by primary care physicians: an international collaborative study. J Clin Psychopharmacol avr. 1999:19(2):132-40.

43. Sigel P, Leiper R. GP views of their management and referral of psychological problems: a qualitative study. Psychol Psychother sept. 2004; 77(Pt 3):279-95.

44. Marquet RL, Bartelds AIM, Kerkhof AJFM, Schellevis FG, van der Zee J. The epidemiology of suicide and attempted suicide in Dutch General Practice 1983-2003. BMC Fam Pract. 4 nov 2005:6:45.

45. Piek E, van der Meer K, Penninx BWJH, Verhaak PFM, Nolen WA. Referral of patients with depression to mental health care by Dutch general practitioners: an observational study. BMC Fam Pract. 26 mai 2011;12:41.

46. Gabbay M, Shiels C, Hillage J. Sickness certification for common mental disorders and GP return-to-work advice. Prim Health Care Res Dev. 2016; 17(5):437-47.

47. Niedhammer I, Chastang J-F, Sultan-Taïeb H, Vermeylen G, Parent-Thirion A. Psychosocial work factors and sickness absence in 31 countries in Europe. Eur J Public Health août. 2013;23(4):622-9.

48. Silva-Junior JS, Fischer FM. Sickness absence due to mental disorders and psychosocial stressors at work. Rev Bras Epidemiol Braz J Epidemiol déc. 2015;18(4):735-44

49. Doki S, Sasahara S, Hirai Y, Oi Y, Matsuzaki I. Absenteeism due to mental health problems and systems for return to work: an internet-based 
unmatched case-control study. Int Arch Occup Environ Health nov. 2016; 89(8):1279-87.

50. Rivière M, Leroyer A, Ferreira Carreira L, Blanchon T, Plancke L, Melchior M, et al. Which work-related characteristics are most strongly associated with common mental disorders? A cross-sectional study. BMJ Open. 05 2018;8(8): e020770.

51. Younès $N$, Rivière $M$, Plancke L, Leroyer $A$, Blanchon T, Azevedo Da Silva $M$, et al. Work intensity in men and work-related emotional demands in women are associated with increased suicidality among persons attending primary care. J Affect Disord. 01 2018;235:565-73.

52. Plancke L, Bavdek R. Les disparités régionales en santé mentale et en psychiatrie. La situation du Nord Pas-de-Calais en France métropolitaine [Internet]. Lille: F2RSM; 2013 p. 46 p. Disponible sur. http://www. santementale5962.com/ressources-et-outils/les-editions-de-la-f2rsm/article/ disparites-regionales-en-sante.

53. WHO. Identification and control of work-related diseases. Report of a WHO Expert Committee. Geneva: WHO; 1985.

54. Lenderink AF, Zoer I, van der Molen HF, Spreeuwers D, Frings-Dresen MHW, van Dijk FJH. Review on the validity of self-report to assess work-related diseases. Int Arch Occup Environ Health avr. 2012;85(3):229-51.

55. Rantanen J, Lehtinen S, Valenti A, lavicoli S. A global survey on occupational health services in selected international commission on occupational health (ICOH) member countries. BMC Public Health. 05 2017;17(1):787.

\section{Publisher's Note}

Springer Nature remains neutral with regard to jurisdictional claims in published maps and institutional affiliations.

Ready to submit your research? Choose BMC and benefit from:

- fast, convenient online submission

- thorough peer review by experienced researchers in your field

- rapid publication on acceptance

- support for research data, including large and complex data types

- gold Open Access which fosters wider collaboration and increased citations

- maximum visibility for your research: over $100 \mathrm{M}$ website views per year

At BMC, research is always in progress.

Learn more biomedcentral.com/submissions 